\title{
AUTOMATIC LOAD FREQUENCY CONTROL OF TWO AREA POWER SYSTEM WITH CONVENTIONAL AND FUZZY LOGIC CONTROL
}

\author{
Nilay.N.Shah ${ }^{1}$, Aditya.D.Chafekar ${ }^{2}$, Dwij.N.Mehta ${ }^{3}$, Anant.R.Suthar ${ }^{4}$ \\ I. Asst.Prof., Electrical Dept., SVIT Vasad, Gujarat, India, ${ }^{2,3,4}$ Electrical Dept., SVIT Vasad, Gujarat, India, \\ nlinshah_svit@yahoo.com,adityachafekar17@gmail.com,dwijmehta37@gmail.com,anantsuthar777@gmail.com
}

\begin{abstract}
The paper presents the controllers to regulate the system frequency. The performance of the controller like PI and Fuzzy Logic are proposed and compared on two area of power system. Fuzzy Logic controllers are found better than the conventional method. Simulations have been performed using Matlab.
\end{abstract}

Key words: Two area frequency power system, PI controller, and Fuzzy logic controller $* * *$

\section{INTRODUCTION}

The main purpose of operating the load frequency control is to keep uniform the frequency changes during the load changes. During the power system operation rotor angle, frequency and active power are the main parameters to change.[13]

In multi area system a change of power in one area is met by the increase in generation in all areas associated with a change in the tie-line power and a reduction in frequency. In the normal operating state the power system demands of areas are satisfied at the nominal frequency. A simple Control strategy for the normal mode is to operates in such a way that

1. Keep frequency approximately at nominal value.

2. Maintain the tie-line flow at about schedule.

3. Each area should absorb its own load changes.

Controller must be sensitive against changes in frequency and load. To analyze the control system mathematical model must be established. There are two models which are widely used,

1. Transfer function model

2. State variable approach.

The most applied controller is Conventional Proportional Integral (PI) [3,6]. It is easier but usually gives large settling time. Most research going on now is based on artificial intelligent systems (fuzzy and neural networks). The inherent gain of these techniques is that they do not require the system model and identification but depend on human expertise knowledge of the behavior.

In this paper, a fuzzy with and without PI controller is proposed and performance comparison is carried out for conventional PI.

\section{TWO AREA SYSTEM}

A two area system consists of two single area systems, connected through a power line called tie-line, is shown in the Figure 1. Each area feeds its user pool, and the tie line allows electric power to flow between the areas. Information about the local area is found in the tie line power fluctuations. Therefore, the tie-line power is sensed, and the resulting tie-line power is fed back into both areas. It is conveniently assumed that each control area can be represented by and equivalent turbine, generator and governor system.

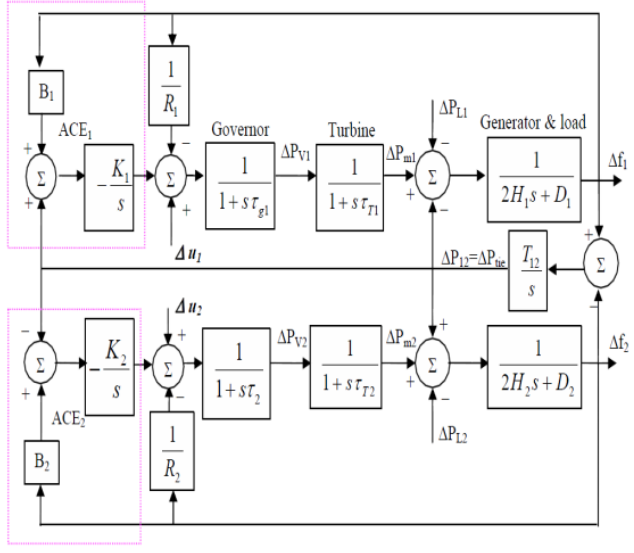

Fig-1: (Two area power system)

Fig. 1 shows the block diagram representing the two area power system. This model includes the conventional integral controller gains (K1, K2) and the two auxiliary (stabilizing) signals $(\Delta \mathrm{u} 1, \Delta \mathrm{u} 2)$. The stabilizing signals will be generated by the proposed fuzzy logic load frequency controller (FLFC). 
Each power area has a number of generators which are closely coupled together so as to form a coherent group, i.e. all the generators respond in unison to changes in the load. Such a coherent area is called a control area in which the frequency is assumed to be the same throughout in static as well as dynamic situation

There exists a maximum on the rate of change of power that can be generated by steam plants. The constraints of the nonlinear characteristics of the turbine control should be considered in the load frequency controller design. If these constraints are not considered in the controller design, the power area is likely to chase large monetary disturbance.

Since a tie line transports power in or out of an area, this fact must be accounted for in the incremental power balance equation of each area.

\section{INTEGRAL CONTROL [14]}

The integral control composed of a frequency sensor and an integrator. The frequency sensor measures the frequency error $\Delta \mathrm{f}$ and this error signal is fed into the integratorThe input to the integrator is called the Area Control Error (ACE).

The ACE is the change in area frequency, which when used in an integral-control loop, forces the s steady-state frequency error to zero.

The integrator produces a real-power command signal $\Delta \mathrm{Pc}$ and is given by

$$
\begin{aligned}
\begin{aligned}
\Delta \mathrm{Pc} & =-\mathrm{Ki} \int \Delta \mathrm{fdt} \\
& =-\mathrm{Ki} \int(\mathrm{ACE}) \mathrm{dt}
\end{aligned} \\
\Delta \mathrm{Pc}=\text { input of speed }- \text { changer } \\
\mathrm{Ki}=\text { integral gain constant. }
\end{aligned}
$$

The value of $\mathrm{Ki}$ is given by below equation. [4]

$$
\mathrm{Ki}=1 / 4 \tau_{\mathrm{p}} \mathrm{K}_{\mathrm{ps}}\left(1+\frac{\mathrm{Kps}}{\mathrm{R}}\right)^{2}=\mathrm{Kcrit}
$$

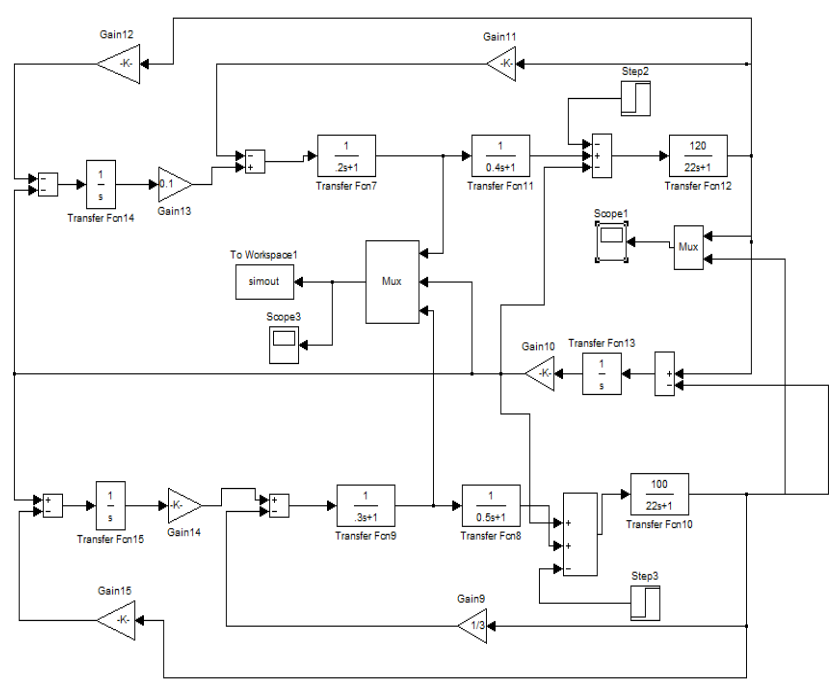

Fig-2: (two areas with PI)

The value of $\mathrm{Ki}$ is so selected that the response will be damped and non-oscillatory.

In this case $\mathrm{Ki}<\mathrm{K}_{\text {crit }}$.

The matlab simulink fig.2 shows the two area frequency controlwithPI

\section{FUZZY LOGIC CONTROLLER}

There are three principal elements to a fuzzy logic controller:

$>$ Fuzzification module (Fuzzifer)

$>$ Rule base and Inference engine

$>$ Defuzzification module (Defuzzifier)

Fuzzy control is based on a logical system called fuzzy logic. It is much close in spirit to human Thinking than classical logical systems. The LFC has been reported in several papers is to maintain Balance between production and consumption of electrical power. Due to the complexity and Multi-variable nature of power systems, a conventional control method has not provided satisfactory solutions.

The fuzzy logic control has tried to handle the robustness , reliability and nonlinearities associated with power system controls. Therefore a fuzzy logic controller (FLC) becomes nonlinear and adaptive in nature having a robust performance under parameter variations with the ability to get desired control actions for complex uncertain, and nonlinear systems without their mathematical models and parameter estimation.

This work proposes a fuzzy controller with up to 49 rules with 7 membership function as negative big (NB), negative medium (NM), negative small (NS), zero (ZE) 
, positive small (PS), positive medium (PM), positive big (PB). For the control of Area control error (ACE), there are two controllers, ACE and d/dt(ACE) [10].

Table- 1 below shows the rules. The rules are interpreted as if ACE is NB an $d / d t(A C E)$ is NS then the output is PM.Triangular membership functions are used for both the inputs and output.

The Defuzzification method employed is the center of area method $[9,11]$. The overall two area system with Fuzzy logic is shown in figure 3 .

Table-1:(Fuzzy rules)

\begin{tabular}{|c|c|c|c|c|c|c|c|c|}
\hline & & \multicolumn{7}{|c|}{ AREA CONTROL ERROR ( ACE ) } \\
\hline & & NB & NM & NS & $\mathbf{Z E}$ & PS & $\mathbf{P M}$ & PB \\
\hline \multirow{7}{*}{$\begin{array}{l}\mathbf{d} / \\
\mathbf{d t} \\
\text { of } \\
\mathbf{A} \\
\mathbf{C} \\
\mathrm{E}\end{array}$} & NB & PB & PB & PB & PB & PM & PM & PS \\
\hline & NM & PB & PM & PM & PM & PS & PS & PS \\
\hline & NS & $\mathrm{PM}$ & PM & PS & PS & PS & PS & $\mathrm{ZE}$ \\
\hline & $\mathbf{Z E}$ & NS & NS & NS & $\mathrm{ZE}$ & PS & PS & PS \\
\hline & PS & ZE & NS & NS & NS & NS & NM & NM \\
\hline & $\mathbf{P M}$ & $\mathrm{NS}$ & NS & NM & $\mathrm{NM}$ & NM & NB & NB \\
\hline & PB & NS & NM & NB & NB & NB & NB & NB \\
\hline
\end{tabular}

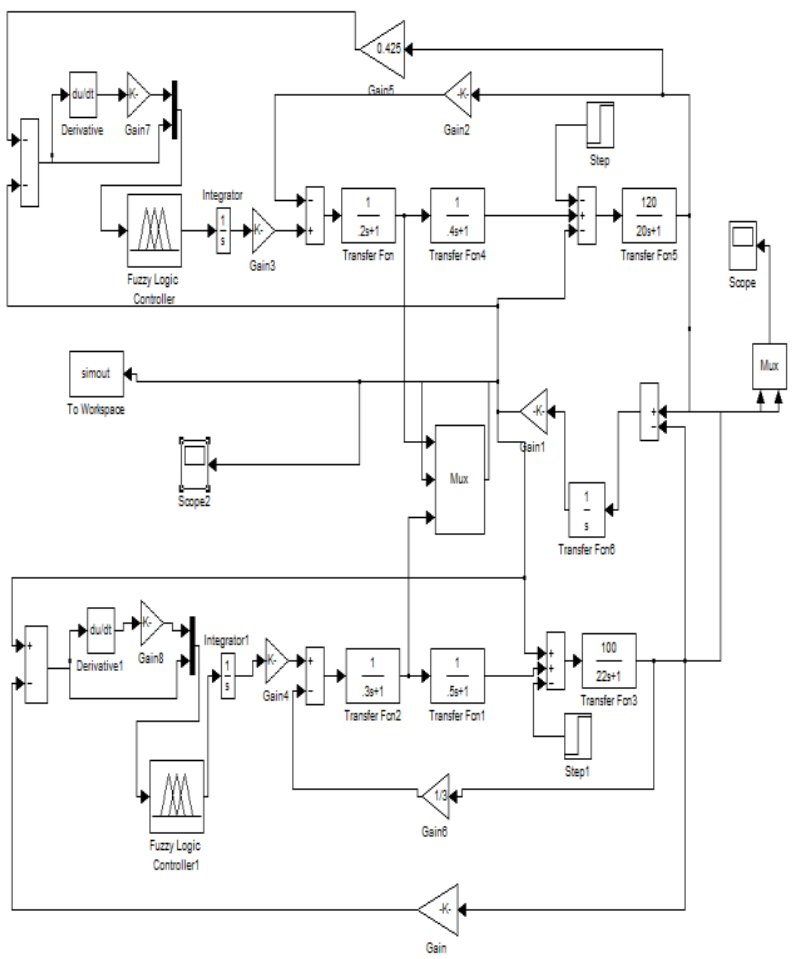

Fig-3 :( Simulink model of two areas fuzzy PI)

\section{SIMULATION AND RESULTS}

The following simulations were performed in order to investigate the performance of the proposed fuzzy logic controller over the conventional integral controller with $2 \%$ change in load of each area with parameters as indicated in Appendix A.

5.1: Simulation is carried out of two area system as per following systems for response of $\Delta \mathrm{fl}$, (see Fig.4)

1. without any controller

2.With PI controller

3. With fuzzy logic controller

4.Fuzzy logic with PI

5.2 Simulation is carried out of two area system as per following systems for response of $\Delta f 2$, (see Fig.5)

1. without any controller

2.With PI controller

3. With fuzzy logic controller

4.Fuzzy logic with PI

5.3 Simulation is carried out of two area system as per following systems for response of Pm1, Pm2 and P12

1. Without any controller (see Fig.6)

2. With PI controller (see Fig. 7)

3. With fuzzy logic controller (see Fig.8)

4. Fuzzy logic with PI (see Fig.9)
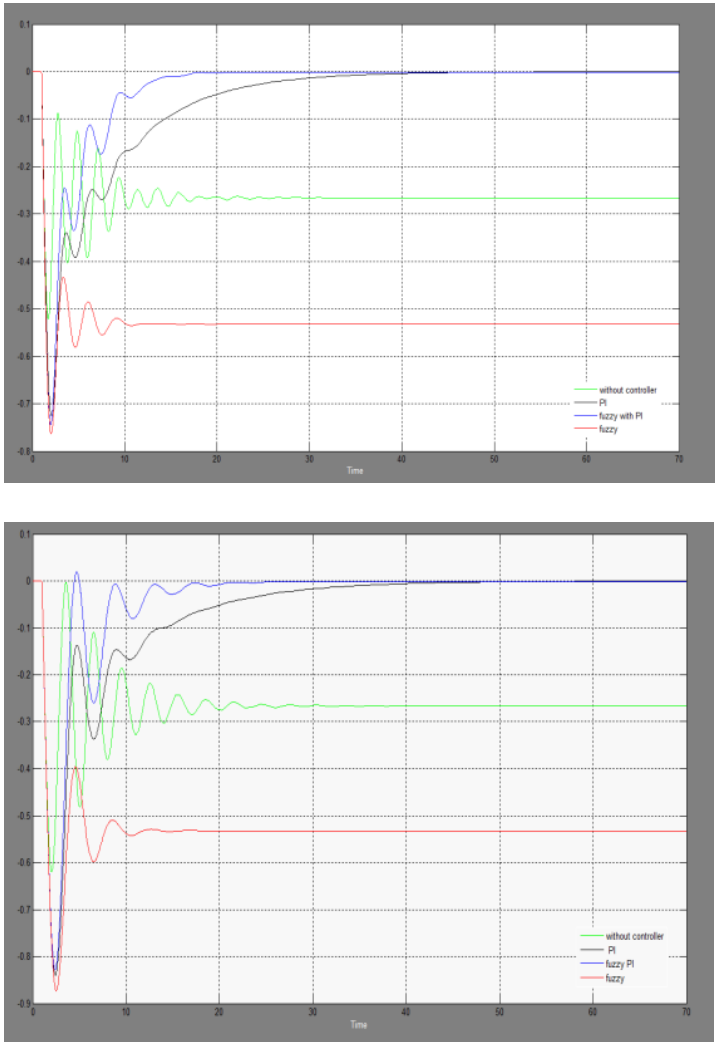

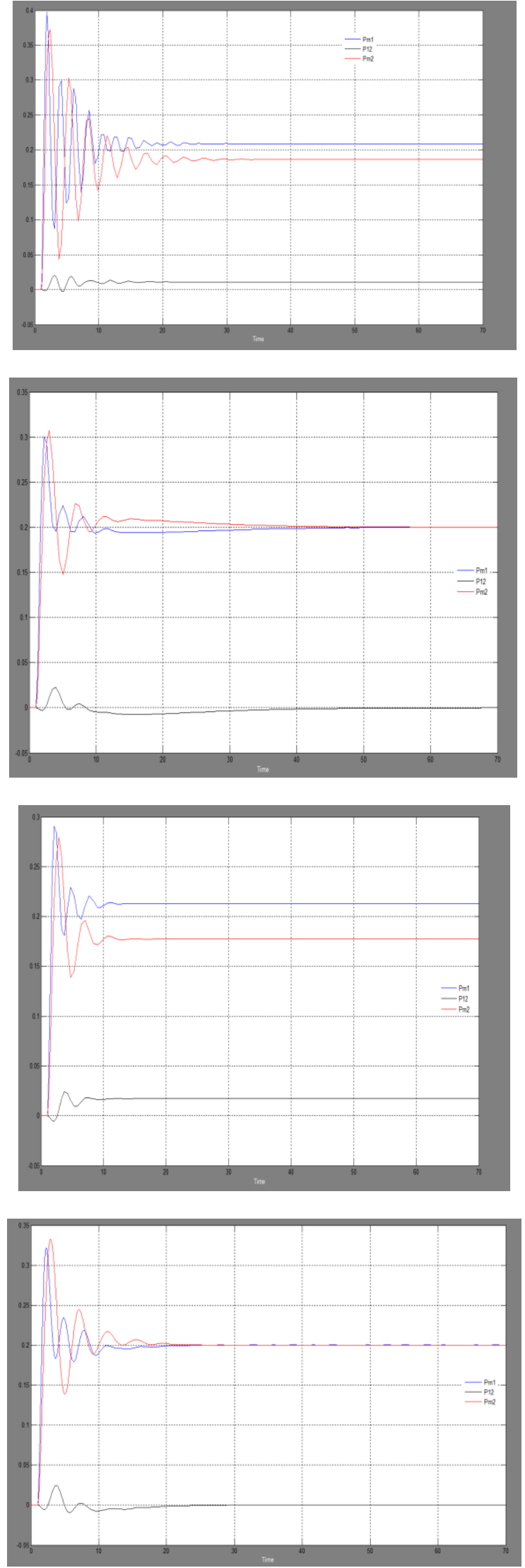

\section{CONCLUSIONS}

In this study an approach of fuzzy logic controller has been investigated for two area frequency control of power system. Results have been compared for step load change against different controller technique mention in the following summary. The result shows the intelligent controller is having more improved dynamic response.

Summary of frequency deviation of $\Delta \mathrm{f} 1$

\begin{tabular}{|c|c|c|c|}
\hline $\begin{array}{c}\text { Type of } \\
\text { controller }\end{array}$ & \%Overshoot & $\frac{\text { Settling }}{\underline{\text { time }}}$ & $\frac{\underline{\text { Steady }}}{\frac{\text { state }}{\text { error }}}$ \\
\hline $\begin{array}{c}\text { Without } \\
\text { controller }\end{array}$ & 7 & 33 & -0.28 \\
\hline PI & 4 & 40 & 0.0 \\
\hline Fuzzy Logic & 2.5 & 15 & -0.52 \\
\hline Fuzzy PI & 4.5 & 23 & 0.0 \\
\hline
\end{tabular}

Summary of frequency deviation of $\Delta f 2$

\begin{tabular}{|c|c|c|c|}
\hline $\begin{array}{c}\text { Type of } \\
\text { controller }\end{array}$ & \%Overshoot & $\frac{\text { Settling }}{\text { time }}$ & $\frac{\underline{\text { Steady }}}{\frac{\text { state }}{\text { error }}}$ \\
\hline $\begin{array}{c}\text { Without } \\
\text { controller }\end{array}$ & 7 & 33 & -0.3 \\
\hline PI & 4 & 40 & 0.0 \\
\hline Fuzzy Logic & 3 & 15 & -0.53 \\
\hline Fuzzy PI & 3.5 & 23 & 0.0 \\
\hline
\end{tabular}

Summary of deviation of Pm1

\begin{tabular}{|c|c|c|c|}
\hline $\begin{array}{c}\text { Type of } \\
\text { controller }\end{array}$ & \%Overshoot & $\frac{\text { Settling }}{\underline{\text { time }}}$ & $\frac{\underline{\text { Steady }}}{\frac{\text { state }}{\text { error }}}$ \\
\hline $\begin{array}{c}\text { Without } \\
\text { controller }\end{array}$ & 7 & 30 & 0.05 \\
\hline PI & 3 & 35 & 0.0 \\
\hline zzy Logic & 2 & 13 & 0.05 \\
\hline Fuzzy PI & 3 & 22 & 0.0 \\
\hline
\end{tabular}

Summary of deviation of Pm2

\begin{tabular}{|c|c|c|c|}
\hline $\begin{array}{c}\text { Type of } \\
\text { controller }\end{array}$ & \%Overshoot & $\frac{\text { Settling }}{\text { time }}$ & $\begin{array}{c}\text { Steady } \\
\text { state error }\end{array}$ \\
\hline $\begin{array}{c}\text { hout } \\
\text { controller }\end{array}$ & 7 & 30 & -0.05 \\
\hline PI & 2 & 35 & 0.0 \\
\hline uzzy Logic & 1.5 & 13 & -0.06 \\
\hline Fuzzy PI & 2.5 & 22 & 0.0 \\
\hline
\end{tabular}




\begin{tabular}{|c|c|c|}
\hline PARAMETERS & $\begin{array}{l}\text { SYSTEM } \\
1\end{array}$ & $\begin{array}{l}\text { SYSTEM } \\
2\end{array}$ \\
\hline $\begin{array}{l}\text { Power system gain constant } \\
, K_{p s}\end{array}$ & 120 & 100 \\
\hline $\begin{array}{l}\text { Power system time constant, } \\
\tau_{p s}\end{array}$ & 20 & 22 \\
\hline Speed Regulation R & 2.5 & 3 \\
\hline Normal frequency, $\mathrm{f}$ & 50 & 50 \\
\hline Governor time constant, $\tau_{s g}$ & 0.2 & 0.3 \\
\hline Turbine time constant, $\tau_{t}$ & 0.4 & 0.5 \\
\hline $\begin{array}{l}\text { Integration time, constant, } \\
\mathrm{Ki}, \\
\mathrm{K}_{\mathrm{i}}=1 / 4 \tau_{p} K_{p s}\left(1+\frac{K p s}{R}\right)^{2}= \\
\mathrm{K}_{\text {crit }}\end{array}$ & 0.1 & 0.15 \\
\hline \multicolumn{3}{|c|}{$\mathrm{T} 12=0.08$} \\
\hline \multicolumn{3}{|c|}{$\Delta \mathrm{X}_{\mathrm{E}}=$ Change in valve position } \\
\hline \multicolumn{3}{|c|}{$\Delta \mathrm{P}_{\mathrm{G}}=$ Change in generation. } \\
\hline \multicolumn{3}{|c|}{$\Delta \mathrm{f}=$ Change in frequency. } \\
\hline$\Delta \mathrm{P}_{\mathrm{TL}}=$ Change in $\mathrm{t}$ & $\mathrm{e}$ - line por & \\
\hline
\end{tabular}

\section{REFERENCES}

[1] Haadi Sadat, "Power Systems Analysis" McGraw-Hill companies Inc. 1999.

[2] Elgerd, O.I, "Electric Energy system theory: An Introduction" McGraw-Hill, TMH edition, 1971

[3] Jawat, T. and Fadel, A, B. "Adaptive Fuzzy Gain Scheduling for Load frequency control", IEEE Trans. on PAS, vol. 14, No 1, February 1999.

[4] Nanda, J. and Kaul, B.L, "Automatic Generation Control of an interconnected power system" IEE Proc. Vol. 125, No. 5, May 1978, pp 385-390.

[5] Fosha, C.E, and Elgerd, O.I. "The Megawatt-Frequency control problem: a new approach via

Optimal control theory, IEEE, Trans. pp 563-577, 1970.

[6] Edison, B, and Ilie, M, "Advanced Generation control: Technical Enhancements, costs, and Responses of market Driven Demand" Proc. of the 57th Annual American Power conf; vol. 57, No. 2, 1995, pp 1419-1427.

[7] Gopal, M, "Modern control system theory" Wiley Eastern Ltd, 2nd edition 1993.

[8] Alden, M, "A Fresh Approach to the LQR problem with Application to power systems"

[9] Indulkar, C.S, and Raj. B, “Application of fuzzy controller to Automatic Generation control, "Electric machines and power systems; vol. 23, No 2, March-April 1995. pp 32-38

[10] Anand, B. And Ebenezer, A.J., "Load Frequency control with fuzzy logic controller considering Nonlinearities and Boiler Dynamic" ICGST-ACSE Journal vol. 8, issue 111, Jan. 2009.

[11] Learning simulink, mathworks, Inc, 2001
[12] Passino K.M, and Yurkovich S., "Fuzzy control, "Addison-Wesley 1998.

[13] S.Sivanagaraju, Gsreenivasan, Power System Operation and Control.

[14] Nilay.N.Shah, Dr.C.D.Kotwal" The State Space Modeling of Single, Two and Three ALFC of Power System Using Integral Control and Optimal LQR Control Method" in IOSR Journal of Engineering March-2012Vol2 (3) pp: 501510.

\section{BIOGRAPHIES:}

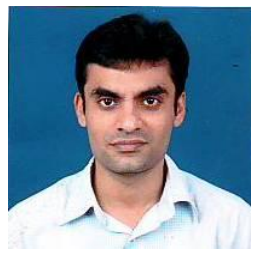

Nilaykumar N. Shah received his M.E. degree from S.P.University of VVNAGAR, Anand, India in 2003. From 2004 he has been a faculty member of Electrical Engineering in Sardar Vallabhbhai Patel Institute of Technology, Vasad, Gujarat, India. His areas of interests are in Power System, Deregulation of electricity market, Power System Operation and Control, AI applications to power system.

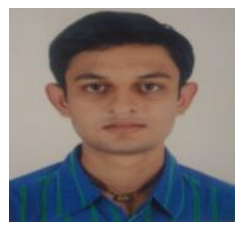

Dwij N. Mehta is pursuing B.E. Electrical (final year) engineering from SVIT

VASAD and presently he is working on his project under guidance of Prof. N.N.Shah.

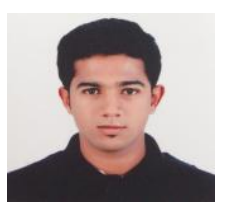

Aditya D. Chafekar is pursuing B.E. Electrical (final year) engineering from SVIT VASAD and presently he is working on his project under guidance of Prof. N.N.Shah.

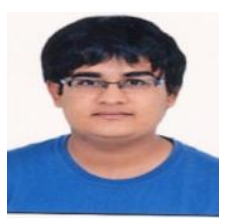

Anant R.Suthar is pursuing B.E. Electrical (final year) engineering from SVIT VASAD and presently he is working on his project under guidance of Prof. N.N.Shah. 